\title{
Geo-spatial Analysis of Land Use Land Cover (LULC) Changes in Oluwa Forest Reserve and its environs
}

\author{
${ }^{* 1}$ TOYINBO, EO; ${ }^{2}$ FASASI, RA; ${ }^{3}$ AGBOR, CF; ${ }^{4}$ FAKOREDE, CO \\ ${ }^{* 1}$ Department of Forest Products Development and Utilization, Forestry Research Institute of Nigeria, Ibadan \\ ${ }^{2}$ Department of Environmental Science, National Open University of Nigeria \\ ${ }^{3}$ Department of Environmental Modelling and Biometrics, Forestry Research Institute of Nigeria, Ibadan \\ ${ }^{4}$ Department of Forest Products Development and Utilization, Forestry Research Institute of Nigeria, Ibadan \\ *Corresponding Author Email: lovemonami@yahoo.com
}

\begin{abstract}
S: Mankind's existence and modification of the landscape have had a profound effect on the natural environment. Anthropogenic activities such as agriculture, mining, deforestation and construction have influenced the shifting patterns of land use. This has resulted in a significant effect on local weather and climate. The use of remote sensing data in recent times has been of immense help in monitoring the changing pattern of vegetation. Therefore this study utilized remote sensing and geographic information system (GIS) methods to identify factors responsible for land use land cover (LULC) changes in Oluwa Forest Reserve between 1984 and 2017. The result showed that Primary forest was reduced by about $5 \%$ between 1984 and 2000 and by about $12 \%$ between 2000 and 2017 and the non-forest got increased by about $4 \%$ and $2 \%$ from 1984 to 2000 and from 2000 to 2017 respectively. Future forecast shows that primary forest will decrease by about $3 \%$ while the non-forest will increase by $5 \%$ by 2034 . The results also revealed that the changes in forest cover between 2000 and 2017 were actively influenced by the closeness of settlements to the forest. It is therefore recommended that the findings of this study should be adopted by relevant authorities as a useful forest management tool.
\end{abstract}

\section{DOI: https://dx.doi.org/10.4314/jasem.v25i7.22}

Copyright: Copyright $(92021$ Toyinbo et al. This is an open access article distributed under the Creative Commons Attribution License (CCL), which permits unrestricted use, distribution, and reproduction in any medium, provided the original work is properly cited.

Dates: Received: 10 May 2021; Revised: 28 June 2021; Accepted: 01 July 2021

Keywords: Oluwa forest, Anthropogenic, Remote Sensing, GIS, LULC.

Forests are natural plantations having canopy covers that are greater than $10 \%$, trees with minimum height of $5 \mathrm{~m}$ and in the absence of other predominant land use (FAO, 2000). Conservation of forests is very vital to the welfare of human beings, in that forests provide essential social, economic and ecological services to mankind if well managed as it requires critical monitoring (Soraya, 2013). Anthropogenic activities such as agriculture, mining, deforestation and construction, influence shifting patterns of land use and are a primary component of many current environmental concerns as land use and land cover (LULC) change is gaining recognition as a key driver of environmental change Sahney et al, Hawksworth et al, 2008; Pimm et al,2014; Ceballos et al, 2017. Forests are valuable resource providing food, shelter, wildlife habitat, fuel, and daily supplies such as medicine ingredients and paper Okunola et al., (2014). Forests play an important role in balancing the earth's carbon dioxide $\left(\mathrm{CO}_{2}\right)$ supply and exchange, acting as a key link between the atmosphere, biosphere, and hydrosphere (Cannel et al.,(1996). Forests are arguably the single most important banks of global biodiversity (Boahene, 1998) but with the current depletion of forested areas around the world, it is important that we manage these renewable resources in a sustainable manner. Nigeria has several

environmental problems that are related to land-cover changes such as flood, desertification, drought, and forests degradation (Shonekan, 1997), and land-use data can serve as systematic data source to help mitigate such environmental issues. There is a need to better understand the relationship between land-use and land-cover changes, and the various land management decisions that drive them. (Woomer, 1993) opined that with a more complete understanding of those drivers, it is possible to predict changes that are likely to occur, and also propose viable management options, this study therefore becomes necessary. Oluwa forest is from inception very close to settlements (whose interference might have contributed greatly to the changes in land-use and land-cover). It is therefore necessary to identify anthropogenic activities causing LULC in Oluwa forest and its environs using "time-series data" from 1984 to 2017.

\section{MATERIALS AND METHODS}

The study area: Oluwa Forest Reserve, situated in the south western part of Nigeria, is located between 
Latitude $6^{\circ} 40^{\prime}$ to $7^{\circ} 59^{\prime} \mathrm{N}$ and Longitude $4^{\circ} 30^{\prime}$ to $4^{\circ} 55^{\prime} \mathrm{E}$. The area covers about $859 \mathrm{~km}^{2}$ and lie on the boundaries of southern Ondo State. The estimated terrain elevation above sea level was 133 metres. The area has a mean annual rainfall of about $2050 \mathrm{~mm}$ and mean monthly temperature of about $27^{\circ} \mathrm{C}$.

Data Collection: Global Positioning System (GPS) was used to obtain ground control points (GCPs) in the field. The geographic co-ordinates of the observation sites from the GPS readings were recorded, and the locations were indicated on the satellite images. During the data collection, the number, the accuracy and the distribution of the GCPs were taken into consideration. Sample points (GPS points) of a LULC type were randomly selected in the field. This was repeated throughout the study area and a total of 100 sample points were picked and these points were used for classification accuracy assessment. A modified version of the Anderson scheme of land use/cover classification was adopted for image classification, the percentage change between 1984 and 2017 were determined using the following formula

$$
\text { (Trend) percentage change }=\frac{\text { observed change }}{\text { Sum of change }} \times 100
$$

Identification of Land Cover Classes and their Spatial Distribution: The comparison of the land use land cover statistics assisted in identifying the percentage change, trend and rate of change between 1984 and 2017. In achieving this, a table showing the area in hectares and the percentage change for each year (1984, 2000 and 2017) measured against each land use land cover type was developed. Percentage change to determine the trend of change was calculated by dividing observed change by sum of changes multiplied by 100

$$
\text { (Trend) percentage change }=\frac{\text { observed change }}{\text { Sum of change }} \times 100
$$

Determination of Trend, Magnitude of Land Use Land Cover Changes: In order to reveal the characteristics of land use changes in the study area, comparison of the land use changes between 2000 and 2017were carried out by weighing the changes by means of Land Use Dynamic Degree (Liu et al., 2010). The formula is as follows,

$$
S=\left(\sum_{I J}^{N}\left(\Delta S_{I-J} / S_{I}\right) \times\left(\frac{1}{T}\right) \times 100\right.
$$

Where $S_{I}$ is the area of land type $i$ in the beginning of the period, $\Delta S_{I-J}$ is the total area of land cover type $I$ converted into other types. $T$ is the study period; and $S$ is the land use dynamic degree in the period of $T$. The values of $S_{I}$ and $\Delta S_{I-J}$ are obtained from cross classification of LULC images between 1984 and 2000, and between 2000 and 2017. The most significant explanatory variables that might lead to forest conversion were examined, analyzed and processed using logistic regression model (LRM) and also the effects of anthropogenic pressure on forest was determined using three distance variables such as distance from forest edge, roads and settlements, and slope position classes as explanatory variables of forest change. Logistic regression model (LRM) was used to model and analyze the forest change.

$$
P(y=1 \mid X)=\frac{\exp \sum(B X)}{1+\exp \sum(B X)}
$$

Where: $\mathrm{P}$ is the probability of the dependent variable being $1 ; \mathrm{X}$ is the independent variables, $X=$ $\left(x_{1}, x_{2}, x_{3}, \ldots x_{k}\right), x_{0}=1 ; \mathrm{B}$ is the estimated parameters,

$B=\left(b_{1}, b_{2}, b_{3}, \ldots . b_{k}\right)$

To linearize the above model the following transformation was applied:

$$
P=\ln (P /(1-P))
$$

By performing the logistic transformation on both sides of the above regression model, standard linear regression model were obtained:

$$
\begin{gathered}
\operatorname{Ln}(P /(1-P))=\left(b_{0}+b_{1} * x_{1}+b_{2} * x_{2}+\cdots+\right. \\
\left.b_{k} * x_{k}+\text { error }\right)
\end{gathered}
$$

Forecast of forest Cover Changes Using CA MarkovBased Model: A raster data model in GIS (CAMarkov-based) was used to represent continuous data over space. The model divided the area into grid cells or pixels. Each grid cell was filled with the measured attribute values in a matrix and cell values were written in rows and columns. The progression of time was modeled as a series of discrete steps with future patterns determined by transition rules which specify the behavior of cells over time. The pixel value of the raster data model in classified images and the simulated images from CA-Markov represents each land. The Markov chain has $\boldsymbol{n}$ states. The data vector is a column vector whose ith component represents the probability that the system is in the ith state at that time. It is important to note that the sum of the entries of a state vector is $\mathbf{1}$. For example, vectors $\boldsymbol{X}_{\boldsymbol{0}}$ and $\boldsymbol{X}_{\boldsymbol{I}}$ in the above example are state vectors. If pij is the probability of movement (transition) from one state $\mathbf{j}$ to state $\mathbf{i}$, then the matrix. 


$$
\mathrm{T}=[\mathrm{pij}]
$$

The CA-Markov analysis was run to test a pair of land cover images and outputs, a transition probability matrix and a transition areas matrix. Classification errors in a map were identified by comparing the map and reference classification at each sample. Kappa coefficient $(K)$ was used to measures pairwise agreement among a set of coders.

Kappa coefficient is being computed as:

$$
k=\frac{\left(N \sum_{i=I}^{r} x_{i i}-\sum_{i=I}^{r} x_{i i}\left(x_{i+} \cdot x_{+i}\right)\right)}{\left(N^{2}-\sum_{I=1}^{R}\left(x_{i+} \cdot x_{+i}\right)\right)}
$$

Where: $\mathrm{N}=$ total number of sites in the matrix; $\mathrm{R}=$ number of rows in the matrix; $x_{i}=$ number in row $i$ and column $i ; x_{+1}=$ total for row $i ; x_{1+}=$ total for column $i$; $x_{i i}=$ total number in row $i$ column $i$

This can be rewritten as:

$$
K=\frac{(\text { Total } x \text { sum of correct pixels })-\text { Sum of the all the }(\text { row total } x \text { column })}{(\text { Total squared }- \text { sum of the all the }(\text { row total } x \text { column total })}
$$

The most common error estimate is the overall accuracy, and was calculated as:

$$
\text { O_ac }=(\text { Sum of diagonal }) / \text { total }
$$

Software: Satellite imagery was processed using the IDRISI software version 17.0.Selva. some statistics of the LULC was carried out using the ArcGIS software version 10.1. Spatial projection of LULC was carried out using CA-Markov in Idrisi.

Data Analysis: Three main methods of data analysis were adopted in the study, Maximum Likelihood Classification and Calculation of the Area in hectares of the resulting land use/land cover types for each study year and subsequently comparing the results. Markov Chain and Cellular Automata Analysis for predicting change Overlay Operations.

\section{RESULTS AND DISCUSSION}

Identification of Forest Cover Classes within the Study Area and their Spatial Distribution: The static land cover distribution for each study year as derived from the images presented in (figure 1, 2, 3) below, there appeared to be a negative change in forest land between 1984 and 2017 with higher rate of change between 2000 and 2017. The secondary forest increased over the years also with higher rate of change between 2000 and 2017 (6.547\% increase) as against $(0.6 \%)$ between 1984 and 2000 . Though there is a general increase in non-forest area, the period between 1984 and 2000 witnessed a higher rate of deforestation as against 2000 and 2017, this might be connected with the report given by Food and Agricultural organization (FAO, 2011) that as at 2005 , Nigeria has the highest rate of deforestation in the world. For example, the non-forest area only increased by $(1.48 \%$ ) between 2000 and 2017 as against the (3.93\%) increase between 1984 and 2000. This is not evident in the changes observed in the forest areas between 1984 and 2017. This shows that loss of forest to human activities occurred most in recent years, increase in the number of people who are dependent on fuel wood consumption might be responsible for this as (Akinbami, 2003) affirmed that the utilization of fuel wood was higher in rural areas and this has been in continuum as rural population increases.

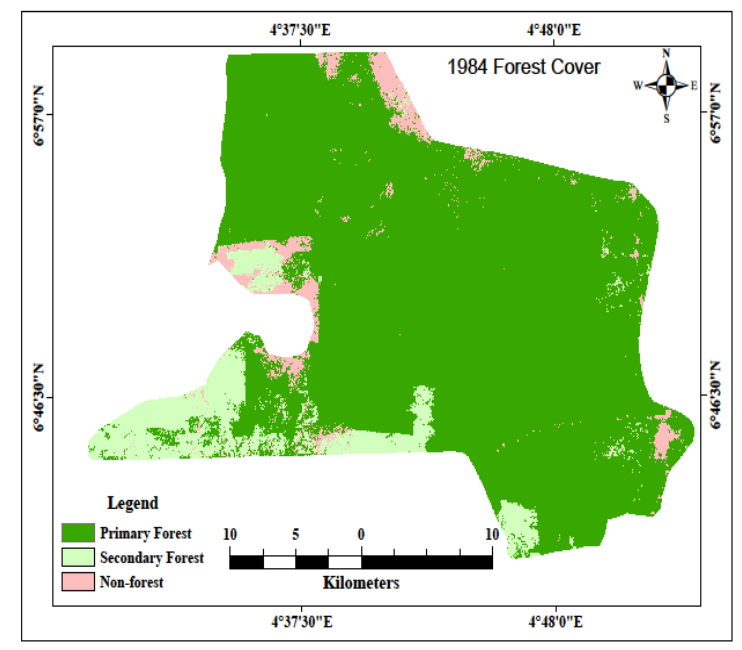

Fig.1: Forest cover for 1984 (Field survey)

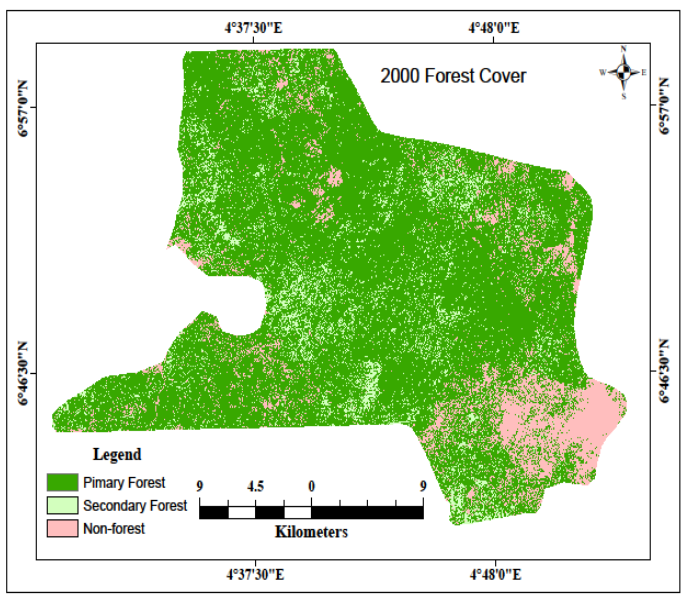

Fig.2: Forest cover for 2000 (Field survey) 


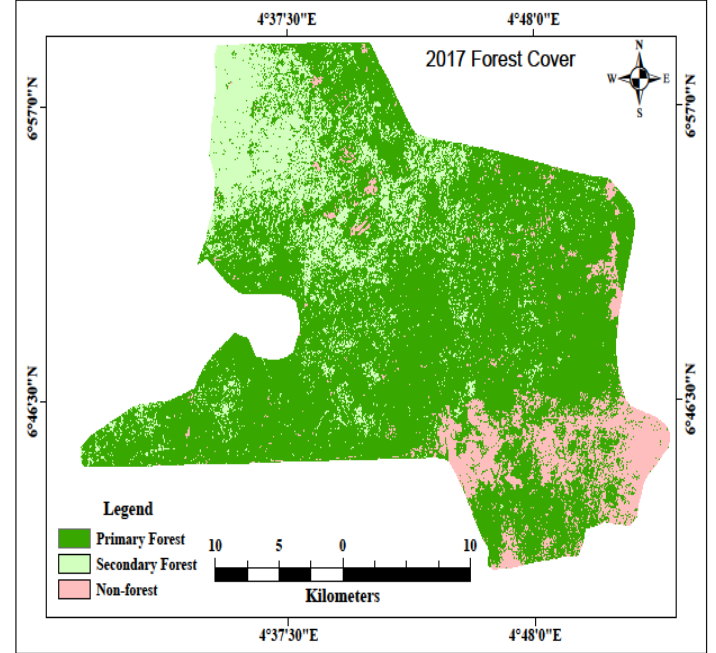

Fig.3: Forest cover for 2017 (Field survey)

The Trend and Magnitude of Forest Cover/Land Cover Changes: From (table 1) below, it is clear that over the years the degree of secondary forest conversion to non-forest area was the highest at $(9.3 \%$ ) this might be attributed to the increase in Nigeria's deforestation rate as reported by $(F A O, 2011)$ and Duveiller et al., (2008) also observed that illegal felling of trees has increased pressure on forest estate. The conversion of secondary forest to primary forest was at (6.8\%) between 2000 and 2017. It was evident that the degree of change of non-forest to forest land was very low, which implies that there has been little or no replacement of lost forest from 2000 till date. This lack of replacement was also observed by (Akinbami, 2003) who revealed that no forest management policies aimed at curbing deforestation has been implemented since 1970 .

Variables Associated With Land Use Land Cover Change: The Cramer's values in table 2 below, showed a significant changes in Primary forest, Secondary Forest and Non-forest in the general land cover conversion over the years. The ROC (Relative Operating Characteristic) values indicate some association between the $\mathrm{X}$ variables and the dependent variable Y. The larger the ROC value, the better the fit. Therefore, one can conclude that the experienced changes in forest cover between 2000 and 2017 were actively influenced by anthropogenic activities (nonforest factors possibly due to development, logging and agriculture). This result is in consonance with the work of Groombridge and Jenkins, (2000) who in their study realized that biodiversity patterns around the world are usually modified by human actions. Road network and physical terrain impacts were relatively fair.

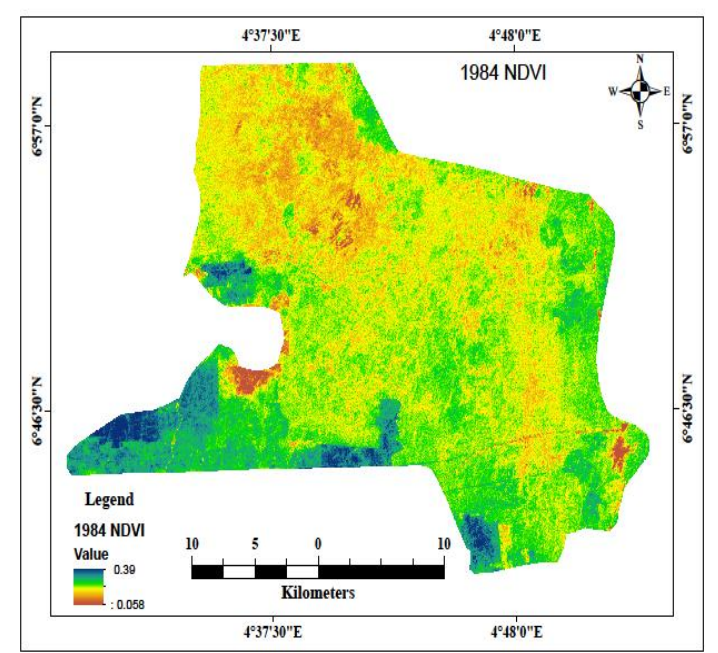

Fig.4: NDVI for 1984 (Field survey)

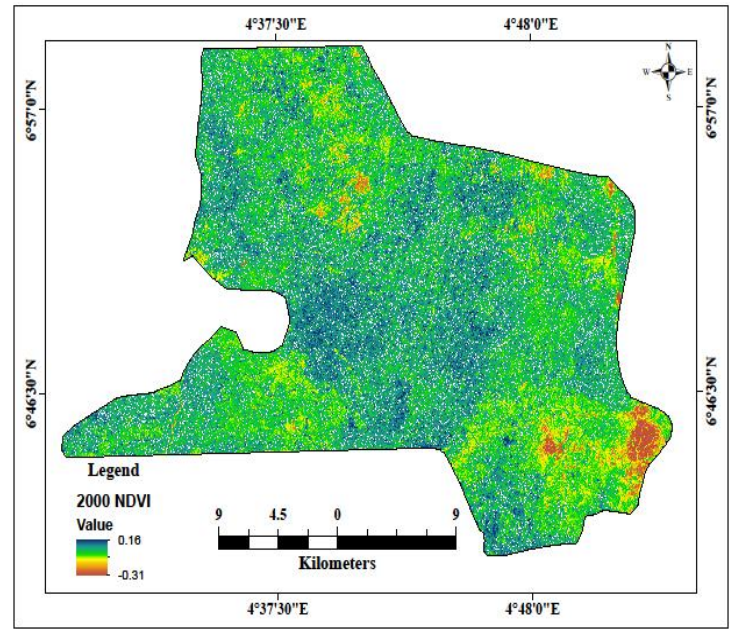

Fig.5: NDVI for 2000 (Field survey)

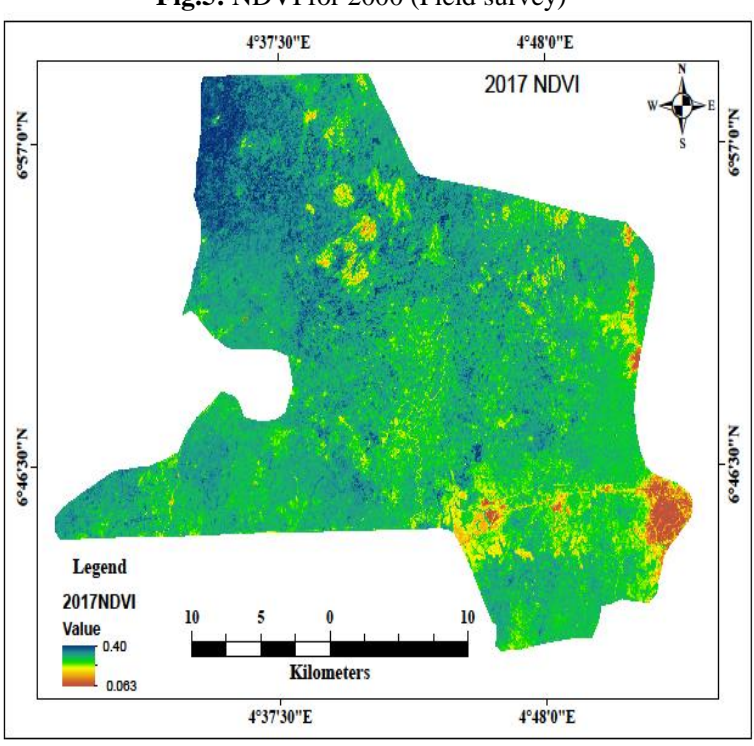

Fig.6: NDVI for 2017 (Field survey) 
Table 1: The Land Use Change Density Between 2000 and 2017 (Field survey)

\begin{tabular}{llll}
\hline & \multicolumn{3}{c}{$\mathbf{2 0 0 0 - 2 0 1 7}$} \\
\cline { 2 - 4 } Land Use Land Cover (LULC) & $\boldsymbol{S}_{\boldsymbol{I}}$ (Ha.) & $\Delta \boldsymbol{S}_{\boldsymbol{I}-\boldsymbol{J}}$ & $\boldsymbol{S}(\boldsymbol{\%})$ \\
\hline Secondary forest to primary forest & 147.250 & 169.9452 & 6.788 \\
Non-forest to primary forest & 88.520 & 1.6074 & 0.0057 \\
Primary forest to secondary forest & 624.090 & 0.1458 & 0.0233 \\
Primary forest to non-forest & 624.090 & 22.446 & 0.212 \\
Secondary forest to non-forest & 147.250 & 13.8168 & 9.38 \\
\hline
\end{tabular}

Table 2: Statistical Test for Association between Dependent and Explanatory variables

\begin{tabular}{lllcc}
\hline Land Cover & & \multicolumn{1}{c}{ Variables } & Crammer's & ROC \\
& Dependent Y & Explanatory X & V & Values \\
\hline Primary forest & Forest change & Distance from primary forest edge & 0.61 & 0.62 \\
Secondary Forest & image with (forest & Distance from secondary forest edge & 0.63 & 0.65 \\
Non-forest & to non-forest and & Distance from non-forest edge (settlement) & 0.71 & 0.81 \\
Road & 'no-change') & Distance from road & - & 0.59 \\
Elevation & categories. & Surface above sea level & - & 0.61 \\
\hline
\end{tabular}

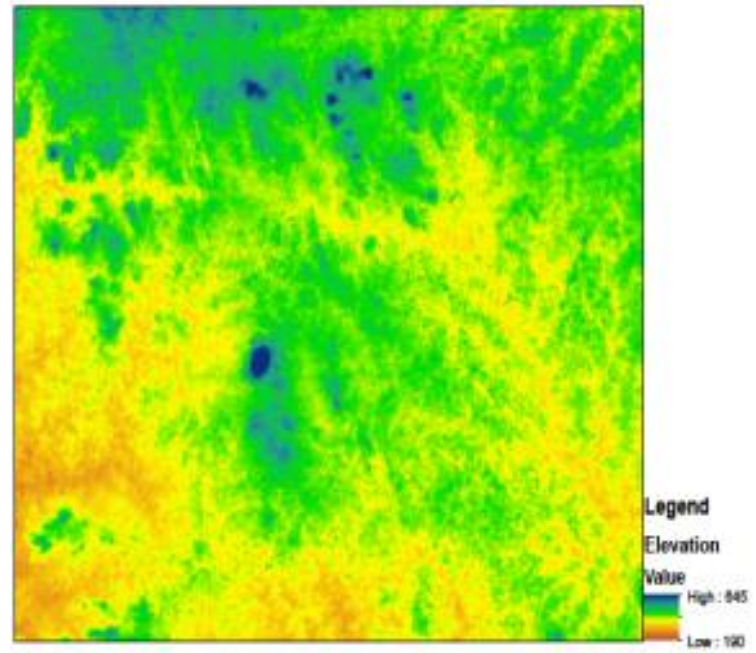

Fig.7: Distance Images of Non-Forest, Road, Primary Forest, Secondary Forest and Elevation

Future Pattern of Forest Cover Changes in the Area: The values presented in (table 3) below, shows projected distribution pattern of forest cover of Oluwa forest reserve. The forest areas have been projected to decrease between 2017 till 2034 if the effects of human activities remain the same. The projection shows an increase in non-forest area indicating increase in lumbering, forest clearing for agriculture and other anthropogenic activities.

Table 4: The Forest Cover Spatial Distribution Statistics (Field

\begin{tabular}{lll} 
& \multicolumn{2}{c}{ survey) } \\
\hline $\begin{array}{l}\text { Forest cover } \\
\text { categories }\end{array}$ & Area $(\mathrm{Km})$ & Area \% \\
\hline Primary forest & 600.60 & 69.85 \\
Secondary forest & 132.07 & 15.36 \\
Non-forest & 127.19 & 14.79 \\
Total & 859.86 & 100 \\
\hline
\end{tabular}

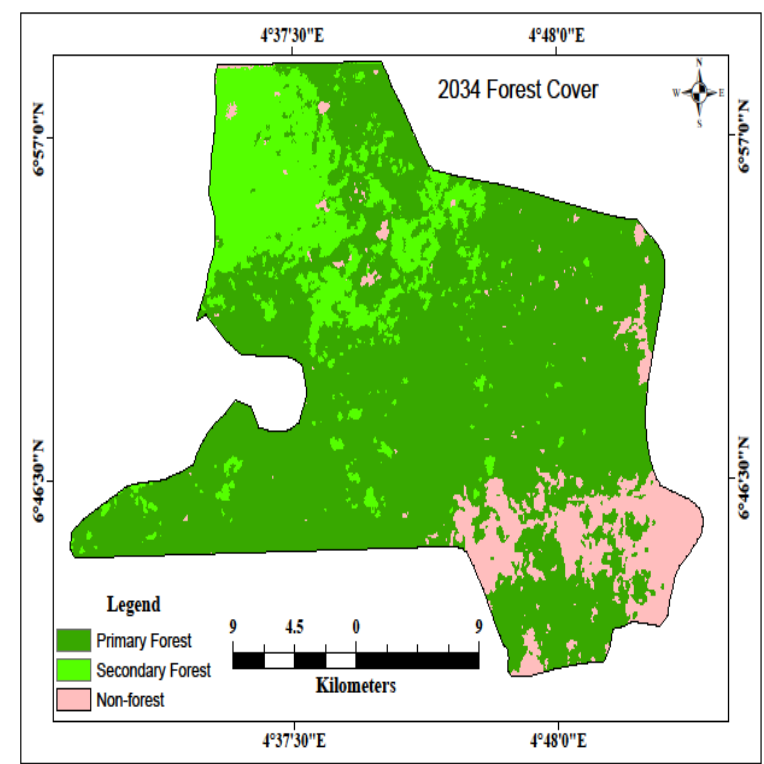

Fig.8: 2034 Projected Forest Cover Changes in the Area (Field survey)

Conclusion: It was established in the course of this study, that remote sensing technique has the capacity to assess forest cover changes. If adequately monitored will help to check mate deforestation and improve the quality of our environment. It was also observed that, the Oluwa forest reserve has undergone dramatic changes in land use and land cover that has resulted in loss of forest land, thus drastically altering the land surface characteristics. Satellite images can therefore be utilized for effective control and management of forest and other land resources.

\section{REFERENCES}

Akinbami, J; (1998). "An Integrated Strategy for Sustainable Forest-energy-environment Interactions in Boahene. The Challenge of Deforestation in Tropical Africa: Reflections on 
Its Principal Causes, Consequences and Solutions. Land Degrad. Develop. 9: 247-258

Cannel; Melvin GR (1996) Forests as carbon sinks mitigating the greenhouse Effect. The commonwealthForestryReview.75 (1) 92-99.

Ceballos; Gerardo; Ehrlich; Paul R; Dirzo, Rodolfo (2017). Biological annihilation via the ongoing sixth mass extinction signaled by vertebrate population loses and declines. Proceedings of the Nat. Academy of Science of the US A. 114(30): E6089- E6096

Duveiller, G P;. Defourny, B; Desclée, and P. Mayaux. 2008. "Deforestation in Central Africa: Estimates at regional, national and landscape levels by advanced processing of systematically-distributed Landsat extracts. Remote Sensing of Environment 112(5): 1969-1981.

FAO, 2011. Assessing forest degradation- Towards the development of globally applicable guidelines. Forest Resources Assessment Working paper 177. Rome.(Available at www.fao.org/docrep015e/j2479e00.pdf.)

Food and Agriculture Organisation (2009). Sustaining Communities, Livestock and Wildlife: A Decision Support Tool. Project Implemented FAO-UN in collaboration with African Wildlife Foundation, ILRI and Government of Tanzania on a GEF/WB fund in Monduli and Simanjiro Districts, Northern Tanzania. Rome, Italy.

Groombridge B; Jenkins, MD (2002). World Atlas of Biodiversity. Prepared by the UNEP
Hawksworth, David L., Bull, Alan T. Biodiversity and Conservation in Europe. Springer. P. 3390 ISBN 978- 1402068645. Nigeria." Journal of Environmental Management 69.2 (2002): 115-28. Science Direct.

Okunola, O A.; AO; Akinyele (2014) Sustainable Management of the Nigerian forest for poverty alleviation. J. of Agric., Forestry and Soc. Sc. Vol 12 No 1 (2014) eLSSN: 1597-0906

Pimm, SL; Jenkins, CN; Abell R; Brooks, TM; Gittleman, JL; Sexton JO (2014). The biodiversity of species and their rates of extinction, distribution, and protection. Science. 344(6187): 1246752 .

Sachney, S; Benton, MJ; Ferry, PA (2010). "Links between global taxonomic diversity, ecological diversity and the expansion of Vertebrates on land" Biology Letters. 6(4): 544-547.

Shonekan, E. (1997). Vision 2010, Federal Republic of Nigeria, Nigeria.

Soraya, V. (2013). Deforestation: Change Detection in Forest Cover using Remote Sensing.

Woomer, P. L. (1993). The Impact of Cultivation on Carbon Fluxes in Woody Savannas of Southern Africa. Water and Soil Pollution 70: 403-412.

World Conservation Monitoring Centre (2005), University of California press. Berkeley. 